\title{
How can we cooperate better? The determinants of conflict solving competence in Polish pediatric nurses' relations with parents of hospitalized children
}

\begin{abstract}
BACKGROUND
Our pilot study carried out at two Polish pediatric hospital departments revealed that conflicts with parents of hospitalized children represent the main concern of pediatric nurses. The aim of this study was to examine factors determining the conflict solving competence in pediatric nurses in order to develop effective communication training programs for pediatric ward staff.
\end{abstract}

\section{PARTICIPANTS AND PROCEDURE}

A total of 78 pediatric nurses completed measures of occupational and perceived stress, conflict modes and competence in solving conflicts with parents of hospitalized children.
RESULTS

The key factor influencing conflict solving competence was the level of perceived stress and supervisor support.

\section{CONCLUSIONS}

Systemic supervised activities aimed at reducing the level of stress, e.g. Balint groups or reflective supervision, could be helpful in mastering the conflict solving competences. Also a paradigm shift from the individual patient to his/ her family considered as a patient could potentially improve nurse-parent relations.

KEY WORDS

pediatric; pediatric nurse-parent relations; stress; conflict solving; nurse-family relations

ORganizations - 1: Institute of Psychology, University of Gdansk, Gdansk, Poland · 2: COPERNICUS PL St. Adalbert Hospital, Gdansk, Poland

Authors' CONTRibution - A: Study design - B: Data collection - C: Statistical analysis - D: Data interpretation -

E: Manuscript preparation · F: Literature search · G: Funds collection

Corresponding Author - Magdalena Chrzan-Dętkoś, Ph.D., Institute of Psychology, University of Gdansk,

4 Bażyńskiego Str., 80-309 Gdansk, Poland, e-mail: psymcd@ug.edu.pl

TO CITE THIS ARTICLE - Chrzan-Dętkoś, M., \& Pietkiewicz, A. (2015). How can we cooperate better? The determinants

of conflict solving competence in Polish pediatric nurses' relations with parents of hospitalized children. Health

Psychology Report, 3(4), 345-351. DOI: 10.5114/hpr.2015.51906

RECEIVED 12.01.2015 · REVIEWED 22.02.2015 · ACCEPTED 13.04.2015 • PUBLISHED 13.07.2015 


\section{BACKGROUND}

The possibility of parental participation during hospitalization of a child is a standard in pediatric healthcare worldwide. Parental care prevents parent-child separation and helps the child cope with hospitalization (Bowlby, 1969, 1980). Although it is assumed unproblematic, evidence exists that nurses often have difficulties in caring for parents of hospitalized children (Coyne, 2008; Roden, 2005; Horn,
Magdalena

Chrzan-Dętkoś, Agnieszka Pietkiewicz Feldman \& Ploof, 1995; Gehring, Widmer, Bänziger, \& Marti, 2002; McCarthy, Power, \& Greiner, 2010; Tekiela \& Zaworska, 2006). The necessity of constant involvement of pediatric nurses in three- or even four-directional communication - with pediatric patients, their parents or caregivers, and pediatricians (Tates, Elbers, Meeuwesen, \& Bensing, 2002) - significantly distinguishes the nature of pediatric ward work from other hospital departments. The complex social environment of the pediatric ward requires appropriate communication skills of the working staff as well as respecting others' viewpoint in order to transform potential conflicts into cooperation. However, the interviews conducted during our pilot study revealed that Polish pediatric nurses identify conflicts with parents of hospitalized children as one of their main work-related concerns (Author blinded, 2012). Another Polish study conducted by Tekiela and Zaworska (2006) showed that most conflicts result from parents of pediatric patients disobeying hospital rules. Such parental behavior was reported by $87 \%$ of nurses participating in this survey. However, similar results were not reported in foreign literature. Therefore, on the basis of Leahey's and Harper-Jacques' (1996) review, we hypothesized that cultural beliefs and values, as well as historical, political and social background, constitute the key to understanding the relationship between Polish pediatric nurses and patient families. The relationship between Polish health care providers and patients/ families is hierarchical in nature, and the patient is assumed to be subordinate to suggestions and decisions of medical staff. According to Lynn-McHale and Deatrick (2000), the lack of reciprocity, which is characteristic for hierarchical relations, may intensify attempts to control, rather than promote mutual cooperation. In such a social context the issue of obeying/disobeying hospital rules becomes a struggle for domination and power. Furthermore, the doctors are traditionally perceived as authorities in our culture, and the patient is not allowed to negotiate with them on a mutual basis. As a result, patients' complaints are often addressed to the nursing staff, occupying an inferior position in the hierarchy of Polish hospitals. Also the socioeconomic situation of Polish public healthcare may stimulate some conflicts between parents and nurses. The political transformation of 1989 was reflected by a long-term financial crisis in public healthcare. Furthermore, the authorities of the majority of pediatric wards cannot afford or do not find it necessary to adapt their facilities for parental needs, although the possibility of hospitalized children being assisted by their caregivers was regulated by law in 1991 (par. 3, pt. 1). For example, parents who accompany their children in hospitals often have to sleep on the floor or chair, do not have a space to prepare something to eat or drink, take a shower, etc. Consequently, they may feel that they are not welcomed in the ward. Also the conditions of hospitalization may additionally enhance the stress and fatigue experienced by the parents.

However, not only parents but also nurses contribute to establishing and maintaining the relationship. For the majority of pediatric medical staff the change in the legal regulations concerning the care of the hospitalized child in 1991 was also very difficult: the pediatric nurses were taught how to take care of children, not of their parents, who often, during the child hospitalization, are overwhelmed with fear and stress. The transition from a pediatric department closed for parents to a pediatric department "welcoming" parents as an important part of the medical team was not obvious and was not accompanied by a systematic workshop.

Furthermore, the nurses may also be affected by stressful conditions of their work. For Polish nurses, the structure of work relations and their position in the hospital power hierarchy may highly contribute to increased stress. According to Karasek's Demand-Control Approach to Stress (Karasek, 1979; Karasek, Baker, Marxer, Ahlbom, \& Theorell, 1981) Polish pediatric nurses may be exposed to situations when they experience a high work demand, along with a relatively small amount of control and social support. In such situations, a higher number of signals can be interpreted as endangering behavior (Jánošová, 2014). The causes of negative behavior are ascribed to personal characteristics rather than external conditions. Therefore, it is easier to speak about a "difficult mother" rather than a "mother experiencing a difficult situation" (Nield-Anderson et al., 1999), which can secondarily influence the nurse-parent communication.

Consequently, one of the challenges for the pediatric nurses is providing, in their complex work environment, the possibility of conversation which would allow all parties of the interaction to be heard out and understood (Levinson, 1997; Tates et al., 2002). A review of the literature revealed that development of cooperation and trust between family and nurse is possible in a nonjudgmental, collaborative and nonhierarchical relationship (Bell, 2009; LynnMcHale \& Deatrick, 2000). The relationship and mutual trust stimulate the involvement of family mem- 
bers in care and support consistent with therapeutic recommendations, and are reflected by their greater satisfaction with the quality of healthcare services (Bell, 2009; Lynn-McHale \& Deatrick, 2000).

Thus, as our pilot study (Author blinded, 2012) revealed that pediatric nurses need support in building satisfying relations with the child's family, with a special emphasis on conflict solving competence, the present research aimed to identify the determinants of conflict solving competence and elaborate practical guidelines for pediatric ward staff that will support their continuous education.

\section{PARTICIPANTS AND PROCEDURE}

\section{DESIGN AND METHOD}

It was a quantitative study, carried out in 2012. The questionnaires were provided to pediatric wards, where they were completed by employed nurses.

The following questionnaires were used in the study:

The Organizational Stress Perception Questionnaire (PSO) by Borucki determines the level of occupational stress associated with a given professional role (Borucki, 1988). The questionnaire comprises 36 statements related to potential feelings associated with a given professional role. The items can be answered using a 5-point rating scale. Theoretically, the global PSO score can range between 36 and 180 points. The higher the score is, the higher is the level of occupational stress. The Cronbach's $\alpha$ reliability coefficient for this tool equaled 92 .

Perceived Stress Questionnaire by Levenstein (PSQ). The PSQ includes 30 items that are assigned to seven scales (Harassment, Overload, Irritability, Lack of Joy, Fatigue, Worries and Tension). The items refer to the period of the last four weeks and can be answered using a 4-point rating scale ( 1 = almost never, 2 = sometimes, $3=$ often and $4=$ usually). The Cronbach's $\alpha$ reliability coefficient for this tool was .92. General PSQ scores are associated with trait anxiety, Cohen's Perceived Stress Scale, depression, self-rated stress and stressful life events (Levenstein et al., 1993).

The Thomas-Kilmann Conflict Mode Instrument (TKI) examines the ways an examined individual deals with conflict. The Thomas-Kilmann Conflict Mode Instrument consists of thirty pairs of statements. For each pair, the respondent must choose either item A or B. The TKI identifies five different styles of conflict: Competing (assertive, uncooperative), Avoiding (unassertive, uncooperative), Accommodating (unassertive, cooperative), Collaborating (assertive, cooperative), and Compromising (intermediate assertiveness and cooperativeness). The TKI has US norms, but a cross-cultural research sample of 6,000 men and women from 16 different countries revealed only minor variations from the US norms. The TKI measures an aspect of conflict-handling behavior that is fairly consistent across different countries and cultures (Herk, Thompson, Thomas, \& Kilmann, 2011). The TKI was modified for the purposes of this study: in the instructions participants were asked to imagine a conflict with parents/ caregivers of hospitalized children while completing a questionnaire.

Pediatric Conflict Solving Scale (PCSS) - a questionnaire assessing the self-perceived competence, related to resolving conflicts with parents of hospitalized children, developed for the purpose of the study. The scale comprised 12 items, each graded using a Likert scale: 1 = never, 2 = rarely, 3 = often, and $4=$ always, e.g. Whenever we experience a conflict with a patient's parents, we comprehensively discuss it within the team; I solve problems in contacts with the patient's relatives together with other nurses. The higher the median score is, the better is the self-perceived ability of solving conflicts. The Cronbach's $\alpha$ reliability coefficient for this instrument was .85 .

The Supervisor Support Scale, developed for the purpose of the study, is a 3-item scale which examines the perception of the supportive role of the supervisor during a nurse's conflict with a pediatric patient's parents (e.g. I can rely on support from my supervisor in the case of conflict with a patient's parents; my supervisor gets involved in solving problems associated with a patient's family). The Cronbach's $\alpha$ reliability coefficient for the 3-item scale was .46.

\section{PARTICIPANTS}

The study included 78 pediatric nurses employed at pediatric wards of hospitals localized in Pomerania province (Poland). Mean age of examined women was 42.70 years, $S D=6.20$, and their mean professional experience was 21.10 years, $S D=7.80$. As many as $65 \%$ of the examined women had secondary education, and $35 \%$ of them possessed higher education. A total of $73 \%$ of examined nurses were employed by a single institution, while the remaining $27 \%$ worked simultaneously in two or more healthcare units.

\section{STATISTICS}

The clinical and demographic information recorded was summarized by descriptive statistics (mean and standard deviation). Relationships between studied variables were analyzed on the basis of Pearson's and Spearman's coefficients of correlation and univariate repeated measures ANOVA. Results were analyzed using the Statistical Package for Social Sciences (SPSS) version 10.0.7 software.
Conflicts between nurses and parents of hospitalised children 


\section{RESULTS}

PEDIATRIC NURSES' CONFLICT MODES USED IN THE CASE OF CONFLICTS WITH PARENTS OF HOSPITALIZED CHILDREN

The univariate repeated measures ANOVA was conducted in order to identify the strategy which was most frequently used for solving conflicts with parents of pediatric patients. The analysis revealed a significant main effect $(F(4,284)=41.60, p<.001)$ of the strategy mode. Post-hoc Bonferroni analysis identified the avoidance and withdrawal strategies as the most frequent ways of solving conflicts with parents of pediatric patients $(p<.001)$, while the competition and forcing strategies proved to be used least frequently $(p<.001)$.

\section{CONFLICT MODES VS. STRESS, SUPERVISOR SUPPORT AND CONFLICT SOLVING COMPETENCES}

To verify whether the frequency of using certain strategies determines the level of experienced occupational and perceived stress, conflict solving competence, and support obtained from a supervisor, a median score for each TKI strategy was calculated. Subsequently, the participants were divided into two groups, with below- and above-average frequency of using each of five studied strategies. The $t$-test analysis revealed that competition and avoidance were the only strategies which significantly differentiated participants. Nurses who used the competition strategy with above-average frequency were characterized by a higher level of perceived stress $(p=.055)$ and higher scores on subscales of PSQ such as worries $(p=.063)$, tension $(p=.035)$ and overload $(p=.018)$. Additionally, they perceived their supervisor support as weaker $(p=.035)$. In turn, nurses who used the strategy of avoidance with above-average frequency showed a lower level of stress than subjects who less often employed this strategy $(p=.005)$ (Table 1$)$.

\section{CONFLICT SOLVING COMPETENCE VS. LEVEL OF PERSONAL AND OCCUPATIONAL STRESS}

Pearson's correlation analysis was conducted to verify the relationship between the self-perceived conflict solving competence of pediatric nurses and their level of perceived and occupational stress. The associations between conflict solving competence and subscales of PSQ such as harassment $(r=-.23, p=.045)$ and lack of joy $(r=-.29, p=.012)$ were observed.

\section{SUPERVISOR SUPPORT, SELF-PERCEIVED CONFLICT SOLVING COMPETENCE AND STRESS}

In order to identify potential differences between individuals who obtained a high level of support from their supervisors and those who did not, the median value of the Supervisor Support variable was calculated. Subsequently, we divided participants into two groups characterized by below- and above-average supervisor's support. The $t$-test was used to verify group differences in the level of experienced stress and self-perceived level of conflict solving abilities. The analysis indicated that supervisor support influences perceived stress $(p=.024)$ and PSQ sub-scales such as overload $(p<.001)$, lack of joy $(p=.017)$, ir-

Table 1

T-test comparison of nurses divided into two groups according to the intensity of conflict modes of competing and avoidance

\begin{tabular}{|c|c|c|c|c|c|c|}
\hline \multicolumn{7}{|c|}{ Competing style of conflict $(M e=0.25)$} \\
\hline & \multicolumn{2}{|c|}{ Below average } & \multicolumn{2}{|c|}{ Above average } & \multirow[b]{2}{*}{$t$} & \multirow[b]{2}{*}{$p$} \\
\hline & $M$ & $S D$ & M & $S D$ & & \\
\hline Perceived stress (PSQ) & 2.22 & 0.43 & 2.42 & 0.39 & 1.96 & .055 \\
\hline Worries & 2.16 & 0.59 & 2.42 & 0.56 & 1.89 & .063 \\
\hline Tension & 1.90 & 0.51 & 2.18 & 0.65 & 2.15 & .035 \\
\hline Overload & 2.39 & 0.46 & 2.67 & 0.51 & 2.42 & .018 \\
\hline Supervisor support & 2.56 & 0.52 & 2.28 & 0.57 & 2.15 & .035 \\
\hline \multicolumn{7}{|c|}{ Avoidant mode of conflict $(M e=0.74)$} \\
\hline & \multicolumn{2}{|c|}{ Below average } & \multicolumn{2}{|c|}{ Above average } & & \\
\hline & $M$ & $S D$ & $M$ & $S D$ & $t$ & $p$ \\
\hline Occupational stress & 2.82 & 0.78 & 2.34 & 0.64 & 2.87 & .005 \\
\hline
\end{tabular}


T-test comparison of differences between nurses who assessed the level of support obtained from a supervisor as above or below average

\begin{tabular}{|c|c|c|c|c|c|c|}
\hline & \multicolumn{4}{|c|}{ Supervisor support $(M e=2.33)$} & \multirow[b]{3}{*}{$t$} & \multirow[b]{3}{*}{$p$} \\
\hline & \multicolumn{2}{|c|}{ Below average $n=43$} & \multicolumn{2}{|c|}{ Above average $n=3$} & & \\
\hline & $M$ & $S D$ & $M$ & $S D$ & & \\
\hline $\begin{array}{l}\text { Self-perceived competenc } \\
\text { in solving conflicts with } \\
\text { parents of hospitalized } \\
\text { children (PCSS) }\end{array}$ & 2.65 & 0.47 & 2.90 & 0.41 & 2.42 & .018 \\
\hline Occupational stress & 2.76 & 0.67 & 2.41 & 0.76 & 2.19 & .032 \\
\hline Perceived stress & 2.42 & 0.38 & 2.20 & 0.44 & 2.31 & .024 \\
\hline Overload & 2.73 & 0.44 & 2.39 & 0.38 & 3.52 & .001 \\
\hline Lack of joy & 2.51 & 0.44 & 2.25 & 0.47 & 2.45 & .017 \\
\hline Irritability & 2.50 & 0.48 & 2.24 & 0.51 & 2.32 & .023 \\
\hline Harassment & 2.09 & 0.50 & 1.86 & 0.59 & 1.91 & .060 \\
\hline Worries & 2.37 & 0.56 & 2.15 & 0.58 & 1.63 & .107 \\
\hline Fatigue & 2.56 & 0.53 & 2.46 & 0.47 & 0.87 & .388 \\
\hline Tension & 2.07 & 0.50 & 2.00 & 0.65 & 0.50 & .620 \\
\hline
\end{tabular}

ritability $(p=.023)$, and harassment $(p=.060)$. Additionally, the nurses with above-average supervisor support scored lower in the level of occupational stress $(p=.032)$ and had higher self-perceived competence in solving conflicts with parents of hospitalized children $(p=.018)$. The results of this analysis are summarized in Table 2.

\section{PERSONAL SITUATION OF PARTICIPANTS VS. CONFLICT SOLVING COMPETENCE}

We found no significant correlations between professional experience, age of the participants and self-perceived conflict solving competence. However, the fact of having children appeared to exert a significant effect on the self-perceived conflict solving competence with pediatric patients' parents.

To conduct the analysis, the participants were divided into four groups:

1) without children $(n=14)$,

2) with one underage child $(n=18)$,

3 ) with at least two underage children $(n=17)$,

4) with only adult children $(n=21)$.

An analysis of variance showed a significant effect $(F(3,67)=4.97, p=.004)$ of bringing up children on conflict solving competences. Post-hoc analyses using the Scheffé post-hoc criterion for significance indicated that the average results on the PCSS were higher in the group of nurses having one underage child $(M=3.05, S D=0.44)$ than in the group of childless nurses $(M=2.52, S D=0.43, p=.010)$ and in the group of nurses having adult children $(M=2.62, S D=0.46$, $p=.025)$. No significant differences were observed between the remaining groups.

\section{DISCUSSION}

Winnicott's statement "There is no such a thing as a baby. A baby cannot exist alone, but is essentially part of a relationship" (Winnicott 1957/2010, p. 89), which can be considered to presage Family System Nursing, implies that while caring for sick children, the professionals take care for their parents as well. As the conflicts with parents of hospitalized children were the major concern for nurses interviewed during our pilot study, we searched for potential determinants of the conflict solving competence amongst our participants.

Our research revealed that conflict modes applied by participating nurses did not exert a significant effect on the self-perceived level of conflict solving competence. However, the competition strategy was associated with a higher level of perceived stress and smaller support obtained from a supervisor. These results are consistent with literature data, such as those of Chan (1981), who observed that competing and avoidance resolution strategies have a negative impact on performance. However, nurses who used the avoidance mode more frequently showed a lower level of stress compared to individuals who used
Conflicts between nurses and parents of hospitalised children 
this strategy more rarely. Although this strategy is described as non-assertive and not associated with team working (Herk et al., 2011), the study of Valentine (1995) shows that members of nursing staff often handle conflicts using the avoidance mode. Similar results, indicating frequent use of the avoidance mode, were observed in other non-manager populations (Revilla, 1984). One may hypothesize that using this strategy helps nurses, who may be overloaded by stress and pressure, which accompany their work, to avoid the involvement of cognitive and emotional resources in conflict situations with parents.

The current study also revealed that self-perceived competence in solving conflicts with parents is associated with such variables as the level of perceived stress, personal situation and supervisor support. Consequently, the level of perceived stress proved a determinant of self-perceived competence in solving conflicts with parents: lower scores on scales related to the lack of joy and harassment were associated with lower conflict solving abilities.

The fact that conflicts were managed better by nurses who possessed one underage child can be explained in terms of their higher empathy and better identification with patients' parents. This identification may be easier as most parents who stay in hospital take care of only one child. One may hypothesize that due to the lack of systemic solutions and opportunities for postgraduate education, some of our nurses seemed to make use of their personal experiences, e.g. related to bringing up children, in handling conflicts with patients' parents.

The present study also indicates that supervisor support is crucial for the self-perceived conflict solving competence. Additionally, supervisor support is associated with a lower level of occupational and perceived stress, which is consistent with the findings of Bartram, Joiner, and Stanton (2004).

In conclusion, activities aimed at reducing the level of stress and involving the supervisor in supporting nurses in their problems with parents of hospitalized children could be reflected by higher personal satisfaction of nurses, as well as indirectly influencing their relationship with the families of the patients. The results also suggest that the stress-overloaded nursing personnel tend to manage conflicts by avoidance or withdrawal from difficult situations with family members. Although this attitude protects nurses from additional strain, it is not always reflected by constructive solutions. Communication training focused on group and team-based methods of conflict management could improve the nurses' conflict solving competences.

Regarding practical guidelines, on the basis of our research and review of the literature, we consider the Balint groups as a form of continuous education, increasing nurses' personal self-efficacy and emotional awareness, which could be recommended and imple- mented in pediatric ward departments. The Balint groups are a kind of team support meetings providing a forum in which health professionals present and attempt to resolve stressful situations with patients and co-workers (von Klitzing, 1999; Rabinowitz, Kushnir, \& Ribak, 1994, 1996).

However, the fact that relations between pediatric nurses and parents require a broader paradigm shift seems to be the most important finding of our study and review of the literature dealing with the problem in question. Not only do behaviors and communication need to be modified, but also the philosophy of the patient-healthcare provider relationship should be changed (Redo \& Bielawska-Batorowicz, 2014). According to Bell (2009), nurses modify their usual patterns of clinical practice in order to stimulate the involvement of families in the therapeutic process. However, the analysis of topics that were addressed during the conferences of Polish pediatric nurses within the last three years suggests that the treatment is still focused on a child instead of including his/her family in the therapeutic process as well. Implementation of the paradigm shift in education and practice would result in perceiving health as more of an "interpersonal phenomenon". Hopefully, social changes taking place in Poland in response to political transformation can facilitate this process. Many people referring to healthcare providers as clients and wanting to obtain their "product" are treated as patients instead. Although such a situation promotes conflict, it can also stimulate future changes.

\section{RefERENCES}

Author blinded. (2012).

Bartram, T., Joiner, T., \& Stanton, P. (2004). Factors affecting the job stress and job satisfaction of Australian nurses: Implications for recruitment and retention. Contemporary Nurse Journal, 17, 293-304.

Bell, J. M. (2009). Family Systems Nursing: Re-examined [Editorial]. Journal of Family Nursing, 15, 123129. DOI: $10.1177 / 1074840709335533$

Bowlby, J. (1969). Attachment. Attachment and Loss (vol. 1). New York: Basic Books.

Bowlby, J. (1980). Loss: Sadness \& Depression. Attachment and Loss (vol. 3). London: Hogarth Press.

Borucki, Z. (1988). Stres organizacyjny [Occupational stress]. Gdańsk: Wydawnictwo Uniwersytetu Gdańskiego.

Chan, M. (1981). Intergroup conflict and conflict management $m$ the $R$ \& $D$ divisions of four aerospace companies (Doctoral dissertation, University of California, Los Angeles). Dissertation $A b$ stracts International, 42, 1767-A.

Coyne, I. (2008). Disruption of parent participation: nurses' strategies to manage parents on chil- 
dren's wards. Journal of Clinical Nursing, 17, 31503158. DOI: 10.1111/j.1365-2702.2006.01928.x

Gehring, T. M., Widmer, J., Bänziger, O., \& Marti, D. (2002). Quality of work and need for supervision among physicians and nurses of a pediatric intensive care unit. Clinical Child Psychology and Psychiatry, 7, 595-608. DOI: 10.1177/ 1359104502007004011

Herk, N. A., Thompson, R. C., Thomas K. W., \& Kilmann, R. H. (2011). International Technical Brief for the Thomas-Kilmann Conflict Mode Instrument. CPP Inc.

Horn, J. D., Feldman, H. M., \& Ploof, D. L. (1995). Parent and professional perceptions about stress and coping strategies during a child's lengthy hospitalization. Social Work in Health Care, 21, 107-127.

Jánošová, J. (2014). Control cognitions as predictors of distress in a cross-cultural context. Health Psychology Report, 2, 227-236. DOI: 10.5114/hpr.2014.46363

Karasek, R., Baker, D., Marxer, F., Ahlbom, A., \& Theorell, T. (1981). Job decision latitude, job demands and cardiovascular disease. American Journal of Public Health, 71, 694-705.

Karasek, R. (1979). Job Demands, Job Decicion Latitude, and Mental Strain: Implications for Job Redesign. Administrative Science Quarterly, 24, 285-308.

Leahey, M., \& Harper-Jaques, S. (1996). Family-nurse relationships: Core assumptions and clinical implications. Journal of Family Nursing, 2, 133-151. DOI: $10.1177 / 107484079600200203$

Levinson, W. (1997). Doctor-patient communication and medical malpractice: implications for pediatricians. Pediatric Annals, 26, 186-193.

Levenstein, S., Prantera, C., Varvo, V., Scribano, M. L., Berto, E., Luzi, C., \& Andreoli, A. (1993). Development of the perceived stress questionnaire: A new tool for psychosomatic research. Journal of Psychosomatic Research, 37, 19-32. DOI: 10.1016/00223999(93)90120-5

Lynn-McHale, D., \& Deatrick, J. (2000). Trust between family and health care provider. Journal of Family Nursing, 6, 210-230. DOI: 10.1177/ 107484070000600302

McCarthy, V. J., Power, S., \& Greiner, B. A. (2010). Perceived occupational stress in nurses working in Ireland. Occupational Medicine, 60, 604-610. DOI: 10.1093/occmed/kqq148

Nield-Anderson, L., Minarik, P., Dilworth, J. M., Jones, J., Nash, P. K., O’Donnell, K. L., \& Stein-Miller, E. A. (1999). Responding to "difficult" patient. American Journal of Nursing, 99, 26-34.

Rabinowitz, S., Kushnir, T., \& Ribak, J. (1996). Preventing burnout: increasing professional self efficacy in primary care nurses in a Balint Group. AAOHN Journal: Official Journal of the American Association of Occupational Health Nurses, 44, 28-32.
Rabinowitz, S., Kushnir, T., \& Ribak, J. (1994). Developing psychosocial mindedness and sensitivity to mental-health issues among primary-care nurses using the Balint group method. Israel Journal of Psychiatry and Related Sciences, 31, 280-286.

Redo, K., \& Bielawska-Batorowicz, E. (2014). Expectations towards medical personnel - a study with infertility clinic patients. Health Psychology Report, 2, 218-226. DOI: 10.5114/hpr.2014.45197

Revilla, V. M. (1984). Conflict management styles of men and women administrators in higher education (Doctoral dissertation, University of Pittsburgh, 1984). Dissertation Abstracts International, 45, $1601 \mathrm{~A}$.

Roden, J. (2005). The involvement of parents and nurses in the care of acutely-ill children in a non-specialist pediatric setting. Journal of Child Health Care, 9, 222-240. DOI: 10.1177/1367493505054419

Tates, K., Elbers, E., Meeuwesen, L., \& Bensing, J. (2002). Doctor-parent-child relationships: a "pas de trois". Patient Education and Counseling, 48, 5-14.

Tekiela, D., \& Zaworska A. (2006). Rodzice w szpitalu. Pomoc czy przeszkoda? [Parents in the child hospital: help or a hindrance?]. Magazyn Pielegniarki i Potożnej, 7-8, 36-37.

Winnicott, D. W. (1957/2010). Dziecko, jego rodzina $i$ świat [The child, the Family and the Outside World]. Warszawa: Oficyna Ingenium.

Valentine, P. (1995). Management of conflict: do women/nurses handle it differently? Journal of Advanced Nursing, 22, 142-149. DOI: 10.1046/j.13652648.1995.22010142.x

von Klitzing, W. (1999). Evaluation of reflective learning in a psychodynamic group of nurses caring for terminally ill patients. Journal of Advanced Nursing, 30, 1213-1221. DOI: 10.1046/j.13652648.1999.01187.x
Conflicts between nurses and parents of hospitalised children 